\title{
Design of Five Parking Lifting Stereo Garage Based on S7-200
}

\author{
Chen Huiqin, Chen Yulin \\ (Department of Electronic Engineering,Southeast University Chengxian College ,Nanjing 210088, Jiangsu)
}

Keywords: lift-sliding ;stereo garage ; control system ; S7-200 ; design

\begin{abstract}
The stereo garage has become an important means and development trends to solve the problem of city's parking difficulty. In this paper, it takes two-layer and five-location of lift-sliding stereo garage for example, instroducing its system structure and working process, focusing on its Component,Software and hardware design base on S7-200. It implements automatic access vehicle, operation monitoring and fault alarm for stereo garage.
\end{abstract}

\section{Introduction}

With the improvement of living standard and the development of economy, automobile into the most families, become the most people's means of transport, but to speed up the process of urbanization, the rapid development of real estate industry, making urban space more and less, the parking problem has become one of the problems urgently to be solved in the city, the traditional plane type parking had gone into a dead end, into the air to parking spaces, implementing stereo parking is solution fast parking problem the only way to big cities, various three-dimensional garage springing up like get rapid development.

Three-dimensional garage type lifting and transferring vertical circulation type, horizontal circulation type, multi circulating type etc.. In developed countries, the application of up-down and translation stereo garage has a history of nearly 30. Japan, Germany and other countries have formed a series of mature technology of up-down and Translation Stereo garage. The up-down and translation has simple structure, convenient operation, according to the safety, reliability, low cost, etc., in the domestic market of the stereo garage occupies an absolute advantage.

The design for the double 5 car lift sliding garage, two layers of three-dimensional design: one layer and two layer. The two layer mobile only lifting board, a horizontal board layer only translational motion. The up-down and translation stereo garage system in a total of six parking spaces, including a vacancy with the template the rise and fall of the channel, the other five spaces with the template can be used for storage of vehicles. A layer of parking spaces for parking or taking the car signals, do not need to move the other five floors for parking and taking out of the car. Second layer of parking spaces for parking or taking the car, should first determine the corresponding layer if the position is empty, if not empty to shift to a layer, until the bottom of the empty to were falling action reach a layer, and then to parking the car, in and out of the car after rising back to its original position. The system structure is shown in figure 1.

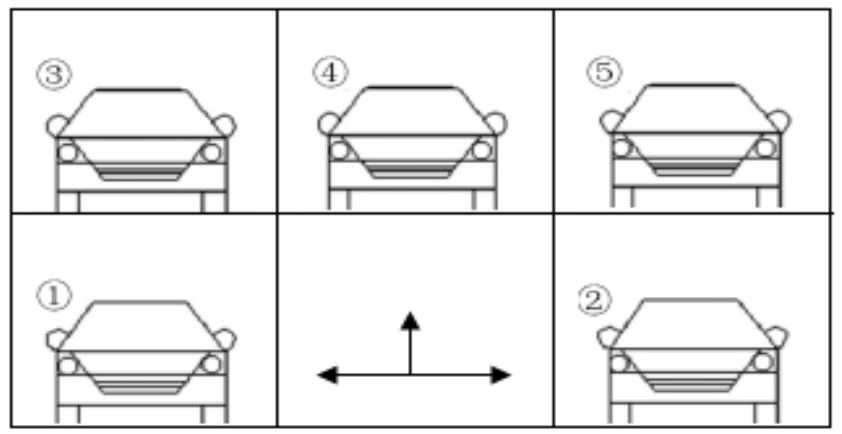

Figure 1. System structure diagram 


\section{Solid Garage System}

\section{1 control section}

Control system of lifting and transferring garage is the vehicle access command center is a prerequisite for realizing intelligent. Mainly consists of the main circuit and control circuit. The main circuit control load the rise and fall of the floors and shifting. The equipment is mainly traversing a small motor and a lifting motor, in order to realize the motor running smoothly, no noise, low energy consumption, high accuracy and high speed, traverse a small motor mainly adopts gear reducer, large lifting motor mainly adopts special belt brake reducer, speed control system using AC variable frequency speed regulation; control circuit is mainly designed for the safety of the car, the various control loops.

The control system is divided into hardware part and software part. The main operating modes of the control system are divided into two types, automatic operation mode and manual operation mode. Refers to the so-called automatic operation mode, when the operator input and out of the garage password and parking number, press confirmation key, remote control and operation system, garage tray lifting and traversing action will automatically, when the set of parking spaces at ground level, users can will drive the car carrying board, or from the car carries the template to remove the car. The automatic mode is mainly used for normal users, the operator input signal remote control operation of the garage. The so-called manual (or point) operation mode operation personnel operated separately continuous or intermittent operation of a certain action, such as a car lift alone, alone shifting, the operation mode for garage management personnel or operation and maintenance personnel to use.

2.2The part of lifting and sliding transmission

Lifting drive is the main part of the garage drive system, which is responsible for the movements of pallet and vehicle. The motor and a chain drive device template from the underlying spaces ascend to the upper parking spaces, or the template from the upper parking fell to the bottom of parking spaces to achieve lift truck access. Lifting drive part is composed of motor, frequency converter, chain wheel, chain and so on. During operating, electric motor drives the chain wheels, the chain wheel drive the chain. The tray move up and down through the control of motor's rotation direction. During access to the vehicle, the lifting system is to be accessed by the vehicle to a designated position by the parking tray or to drop the tray carrying the vehicle from the specified position.

Transverse transmission system is responsible for parking tray's movement on the beam. Traversing transmission mechanism consists of motor, inverter, driving wheel and rail. Bottom traverse drive system are integrated with vehicles, transverse transmission system of the other layers are placed on the parking frame. Drive shaft work performance is good or bad will directly affect the working condition of the whole garage. According to the working principle of the lift-sliding stereo garage, car carrier, except the top layer one, should move left and right through sliding rail in each layer. With these movement, the upper car carrier will have enough space.

2.3 Steel structure frame

The steel frame structure is mainly composed of beams, rails, rails, racks and tray components. The main function of this structure is for bearing, a number of parking spaces, and the installation of mechanical transmission, electrical control, fire control systems, drainage and other related equipment. Frame structure is the supporting part of the whole garage. The main frame system is built by the connection of horizontal beam and vertical column's steel nodes.

\section{Design of lifting and transferring parking control module}

\subsection{Selection of control hardware}

Control system is an important equipment of three-dimensional garage, which directly affects the working efficiency of the garage. The control system should have the features of reliability, easy operation, import and export automatically. The control system mainly consists of the host, 
contactor, circuit breaker, travel switch, limit switch, photoelectric switch and so on. Besides, as an industrial automation controller, PLC has high reliability, strong anti-interference ability, small volume, good versatility, convenient use. Therefore, this study selects S7-200 CPU 226 PLC as the core of the control system manages and monitor garage.

\subsection{Composition of control system}

The control system mainly consists of hardware system and software system, and its structure is shown in Figure 2.

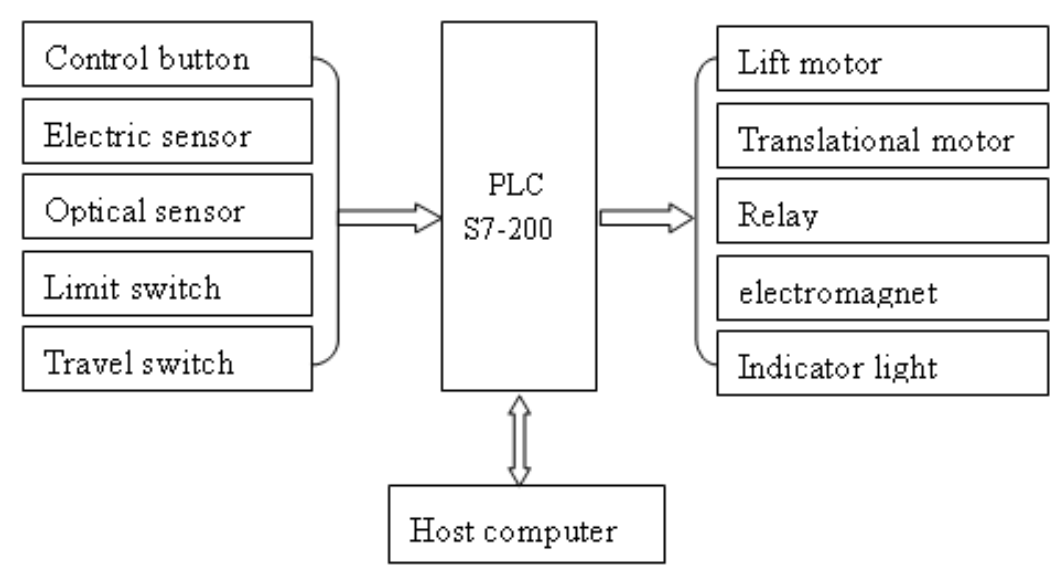

Figure 2. System architecture diagram

The main control object of the control system is to traverse a small motor and lift a large motor. These motors will operate through press of control button based on the customs' purposes. Change of the power phase will achieve the car carriers' movement. Besides, the other control object is a variety of auxiliary devices, such as detection device and its various security facilities, etc..

Process during up and down motion is the most prone to problems. Therefore lift system with inverter drives the lifting motor. While deceleration device will control the lifting speed. Travel switch positioning is taken in order to ensure the car carrier dropping at the specified location. The photoelectric switch is used to determine whether there is a vehicle on the car carrier. Besides, anti-falling system with anti-falling electromagnet is used in the second floor parking space to prevent car drop. Safety hook system will be opened with power and locked without power. Then, it can prevent parking space dropped because of wire fracture at power-off condition.. Detection signal sending by the detection device is to ensure the precise positioning of the parking spaces and security. Required testing devices conclude parking spaces left in place, right in place, on the upper limit, under the place, the safety hook open and other detection devices. The control principle is shown in figure 3 .

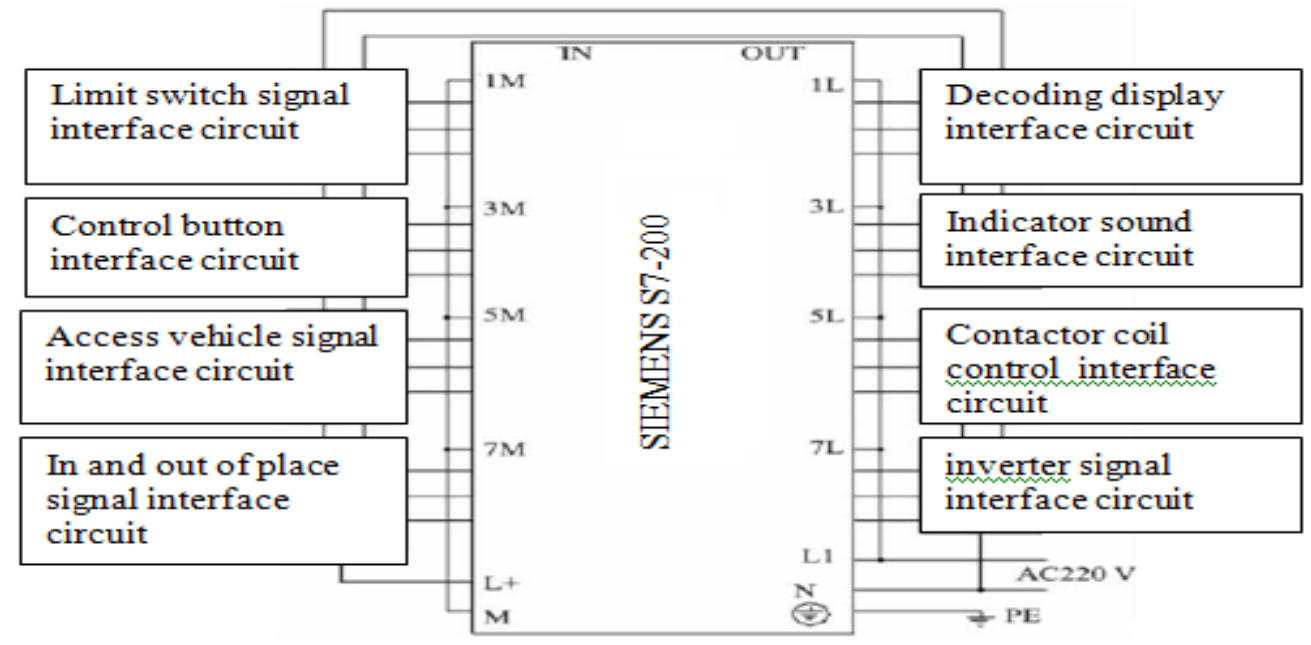

Figure 3. Principle control diagram

3.3 Design of control program 


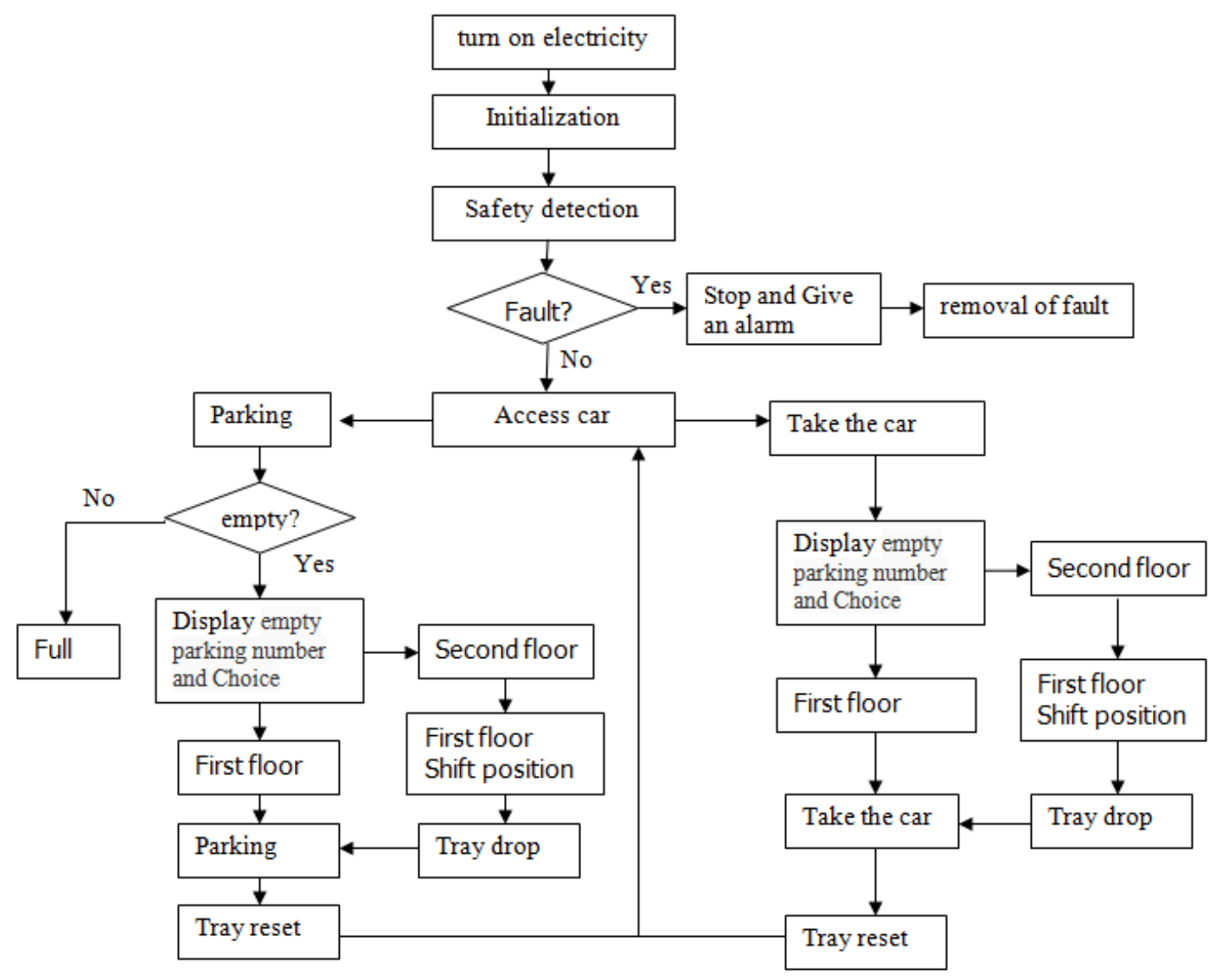

Figure 4.Software flow chart

PLC control system is mainly aimed to complete the operation of storage and taking vehicles automatically. The control program is designed with modular structure, which is composed of initialization program, main control program and fault alarm program. Initialization program is mainly to scan the port and the state, then transfer to the corresponding program according to the results of the tests. In access to vehicles, if driver choose parking space in layer one the driver can directly drive the car into the parking space or out of the car carrier. While if driver choose the layer two, PLC control program can determine the parking space in layer one just below the chosen one whether is free. Then the car carrier will drop when it is free. Otherwise, the car carrier will be moved and free the space firstly. Once complete the car storage or car taking, system will reset automatically and wait for the next operation instructions.

When the vehicle is too long or overweight, or there are some other security risks, the fault alarm program will be sent to the sound and light signal alarm, while the system will stop all actions, clear all ports and prompt troubleshooting. The flow chart of the control program is shown in figure 4.

\section{Conclusion and Prospect}

The characteristics of lift-sliding stereo garage are focused on the modern control, especially the advanced technology of PLC control, high scientific and technological content of the garage. The lift-sliding stereo garage have the features of parking convenience, fast access speed, flexible garage structure, low cost, safety and so on. It will become the main form of the future urban parking development. The Siemens S7-200 PLC and PC as main control units are taken to design the double parking lifting and transferring type garage with the technology of mechanical design, mechanical transmission, control technology, detection technology and touch screen and so on. This system has the advantages of simple operation, high performance but low price, good stability and can increased I / O points through PLC to facilitate expansion. This lift-sliding stereo garage increases the layers and parking garage, meet the requirements of different space size. 


\section{References}

[1]Mei lian,Ten Xuna,Xiong Guangjie etc.Design of stereo garage control system based on PLC[J]. MicrocomputerInformation,2009(25):42-44.

[2]He Yongjun,Yang Chengchao,Zhou Xuhong etc. The structure form, application and development of stereoscopic garage[J]. Journal of Architecture and Civil Engineering,2009:31-34.

[3] Ma Honglin. Lifting and sliding type stereo garage based on PLC control[M]. Intelligent Building and City Information,2007:85-89.

[4]Liu Yiwei. Design of stereo garage control system based on PLC[J]. Science Technology and Engineering,2011(9).

[5] Huaizhou. PLC multilayer up-down and translation stereo garage control system design based on [J]. electronic design application, 2005 (4): 100 - 102. 